\title{
STRATEGI PEMASARAN DENGAN OPTIMALISASI PROMOSI, KELAS SOSIAL DAN CITRA MEREK UNTUK PENGAMBILAN KEPUTUSAN KONSUMEN UNTUK BERBELANJA ONLINE
} (STUDI KASUS DI MATAHARIMALL.COM)

\author{
MARKETING STRATEGY WITH PROMOTIONAL OPTIMIZATION, SOCIAL CLASS AND BRAND \\ IMAGE FOR CONSUMER DECISION MAKING TO SHOP ONLINE (CASE STUDY IN \\ MATAHARIMALL.COM)
}

\author{
Dian Nur Mastuti ${ }^{1}$ Yuniatin Trisnawati DKW ${ }^{2}$ \\ Sekolah Tinggi Ilmu Ekonomi AUB Surakarta
}

\begin{abstract}
ABSTRAK
Penelitian ini bertujuan untuk mengetahui Strategi Pemasaran dengan Optimalisasi Promosi, Kelas Sosial dan Citra Merk untuk Pengambilan Keputusan Konsumen untuk Berbelanja online (Studi Kasus di Mataharimall.com). Penelitian dilakukan pada konsumen mataharimall.com di kota Surakarta dengan sampel sebanyak 100 orang dengan metode purposive sampling dengan menggunakan kuesioner.

Analisa Data menunjukkan hasil bahwa seluruh pertanyaan yang digunakan dalam kuesioner valid dan reliabel. Hasil uji asumsi klasik menunjukkan bahwa seluruh data normal, tidak terjadi heterokesdastisitas, tidak terjadi multikolineriaritas serta tidak terjadi autokorelasi. Hasil uji regresi berganda dan uji t menunjukkan bahwa Variabel promosi berpengaruh positif tidak signifikan terhadap keputusan, Kelas sosial berpengaruh negatif tidak signifikan terhadap keputusan, dan Citra Merk berpengaruh positif tidak signifikan terhadap keputusan. Hasil uji $\mathbf{R}^{2}$ menunjukkan hasil bahwa Promosi, Kelas sosial dan citra merk hanya mampu menjelaskan variabel Keputusan Konsumen untuk berbelanja online sebesar $8 \%$, sedang sisanya dipengaruhi oleh variabel di luar penelitian.
\end{abstract}

Kata kunci : Promosi, Kelas Sosial, Citra merk, Keputusan

\section{ABSTRACT}

This study aims to determine the Marketing Strategy with Promotion Optimization, Social Classes and Brand Image for Consumer Decision Making for Online Shopping (Case Study at Mataharimall.com). The study was conducted on consumers of suryamall.com in Surakarta city with a sample of 100 people using purposive sampling method using a questionnaire.

Data analysis shows that all the questions used in the questionnaire are valid and reliable. The classic assumption test results show that all data are normal, there is no heterokesdasticity, there is no multicollinarity and there is no autocorrelation. The results of multiple regression test and t test show that the promotion variable has a positive and insignificant effect on the decision. Social class has a negative and insignificant effect on the decision, and the Brand Image has a positive and insignificant effect on the decision. $R 2$ test results show that promotion, social class and brand image are only able to explain Consumer Decision variables to shop online at 8\%, while the rest are influenced by variables outside ofresearch.

Keywords: Promotion, Social Class, Brand Image, Decision

\section{PENDAHULUAN}

Dalam satu dekade terakhir, perkembangan teknologi semakin nyata dan merata ke segala penjuru dunia. Internet menjadi salah satu teknologi yang maju dengan pesat dan mempengaruhi segala bidang kegiatan serta berisi segala jenis informasi di dalamnya. Segala informasi dapat diakses dengan sangat mudah dan lengkap melalui media - media elektronik terutama telepon seluler yang telah dimiliki oleh hampir seluruh orang di penjuru dunia. 
Data dari Depkominfo menyatakan pengguna Internet di Indonesia hingga tahun 2014 mencapai 82 Juta orang dan menduduki peringkat ke 8 pengguna internet di dunia. Dari jumlah tersebut, $80 \%$ diantaranya adalah remaja berusia 15-19 tahun. Untuk pengguna facebook, Indonesia berada di peringkat ke 4 besar dunia. Sedangkan data dari Asosiasi Penyelenggara Jasa Internet Indonesia (APJII), sampai Januari 2016 pengguna internet di Indonesia telah mencapai 88,1 juta, dimana 48\% diantaranya merupakan pengguna internet harian.

Fenomena ini memberikan dampak kepada dunia usaha khususnya bisnis dan perdagangan. Strategi pemasaran beralih dari strategi tradisional menjadi strategi modern dengan memanfaatkan teknologi internet. Pasar perdagangan dan penjualan mengikuti perkembangan zaman menjadi pasar e-commerce. Pertumbuhan e-commerce meningkat sejalan dengan peningkatan pengguna internet dan kepercayaan masyarakat akan keamanan bertransaksi elektronik.

Menurut riset Markplus Insight dan majalah online Marketeers tahun 2013, dari 74,6 juta pengguna internet di Indonesia, 20\% melakukan belanja online. Sedang menurut riset Online Shopping Outlook 2015 yang dikeluarkan oleh BMI research mengungkap kan nilai belanja online pada 2014 mencapai nilai 21 triliun. Menurut riset dan penelitian firma konsultan bisnis dan manajemen AT Kearny, nilai penjualan global e-commerce tahun 2015 hampir mencapai 1 triliun dolar Amerika atau tumbuh sebesar 18\% dibandingkan tahun2014.

Pasar e-commerce menawarkan berbagai jenis barang yang diperdagangkan melalui situs situs penjualan online seperti Bukalapak, Lazada Indonesia, Tokopedia, OLX Indonesia, serta Elevenia menjadi situs yang sangat populer dan banyak dikunjungi netizen serta memiliki omzet sampai hampir 150 triliun rupiah.

Melihat tren positif yang yang terus berkembang ini, sejak bulan September tahun 2015 Matahari department store mulai mengikuti perkembangan dan membuka situs penjualan online yang diberi nama mataharimall.com sebagai wujud perluasan usaha ke e-commerce. Pada awal peluncurannya, Mataharimall.com menawar kan berbagai program promo spektakuler, yaitu SuperSeptember yang terdiri dari tiga program super, yakni Super Prizes, Super Surprise Deals, and Super Cicilan. Selama tiga bulan setelah peluncurannya, MatahariMall.com mampu mengumpulkan pelanggan hingga 200 ribu orang dan memiliki karyawan sekitar 402 orang di dua lokasi kantor dan masih terus berkembang hingga saat ini. Model promosi yang terus dikembangkanpun baru dan berbeda dengan online store yang lain sehingga menarik minat konsumen.

Minat dan keputusan konsumen untuk memilih suatu produk dan tempat berbelanja dipengaruhi oleh berbagai faktor, baik dari segi ekonomi, psikologi ataupun lingkungan. Dari segi Ekonomi, Kelas sosial dan Promosi berupa paket Diskon dan program yang didesain menarik dapat mempengaruhi bagaimana konsumen memandang suatu produk, serta tempat berbelanja serta menentukannya sebagai pilihan. Dari segi Psikologi, persepsi merk adalah beberapa hal yang mempengaruhi keputusan konsumen untuk berbelanja di suatu tempat tertentu.

Keputusan adalah seleksi terhadap dua pilihan alternatif atau lebih. Dengan kata lain, pilihan alternatif harus tersedia bagi seseorang ketika mengambil keputusan. Jika seseorang mempunyai pilihan antara melakukan pembelian atau tidak, orang itu berada dalam posisi mengambil keputusan. (Schifman dan Kanuk, 2007). Keputusan konsumen untuk memilih berbelanja di Mataharimall.com dibandingkan dengan online store dapat dipengaruhi oleh berbagai hal diantaranya promosi, diskon, kelas sosial dan persepsi merk.

Promosi merupakan kegiatan yang dilakukan perusahaan dalam upaya mengkomunikasikan suatu produk kepada konsumen sehingga dapat mempengaruhi minat beli konsumen terhadap produk perusahaan. Aktivitas yang mengkomuni kasikan keunggulan produk dan membujuk pelanggan sasaran untuk membelinya (Kotler dan Armstrong, 2009). Berbagai jenis program promosi dilakukan oleh matahari diantaranya Diskon dan Gratis biaya kirim. Selain itu program baru yang sedang berjalan saat ini adalah Online-to-Offline $(\mathrm{O} 2 \mathrm{O})$ yakni barang-barang yang dibeli bisa diambil dan dikembalikan di 131 gerai Matahari Departement Store yang tersebar di seluruh Indonesia,serta pembayaran bisa dilakukan secara offline, juga lewat departement store Matahari.

Kelas sosial dibedakan dari berbagai hal diantaranya harta, pendidikan, pendapatan dan 
gengsi. Semakin tinggi kelas sosial konsumen, mereka cenderung memilih untuk melakukan transaksi di tempat yang terjamin kualitasnya. Harga bukan masalah besar sepanjang gengsi terpenuhi, kepuasan diperoleh dan kualitas barang tidak mengecewakan. Penelitian tentang pengaruh kelas sosial terhadap keputusan pembelian yang dilakukan oleh Rozikin, Leonardo dan Andi (2015) menunjukkan hasil bahwa kelas sosial berpengaruh positif terhadap keputusan pembeliankonsumen.

Merek pada hakikatnya untuk segala jenis produk (barang, jasa, pengecer,bisnis online, orang, organisasi, tempat dan gagasan) yaitu dengan cara memberikan nama pada produk dan menyertakan makna atau arti khusus menyangkut apa yang ditawarkan produk bersangkutan dan apa yang membedakannya dari produk - produk pesaing (Keller 2008: 352). Bagi konsumen, Merek adalah sesuatu yang sangat penting dalam keputusan pembelian. Konsumen biasanya memiliki persepsi dan perasaan yang kuat terhadap merek - merek tertentu, bahkan mengutamakan merek diatas harga atau faktor lain yang mempengaruhi keputusanpembelian.

Rumusan Masalah dalam penelitian ini adalah : 1. Untuk mengetahui secara empiris pengaruh Promosi terhadapKeputusan Konsumen untuk berbelanja online di Mataharimall.co, 2. Untuk mengetahui secara empiris pengaruh Kelas Sosial terhadap Keputusan Konsumen untuk berbelanja online di Mataharimall.com, 3. Untuk mengetahui secara empiris pengaruh Citra Merek terhadap Keputusan Konsumen untuk berbelanja online di Mataharimall.com

Tujuan Penelitian adalah : 1. Untuk mengetahui secara empiris pengaruh Promosi terhadap Keputusan Konsumen untuk berbelanja online di Mataharimall.com, 2. Untuk mengetahui secara empiris pengaruh Kelas Sosial terhadap Keputusan Konsumen untuk berbelanja online di Mataharimall.com, 3.Untuk mengetahui secara empiris pengaruh Citra Merek terhadap Keputusan Konsumen untuk berbelanja online di Mataharimall.com

\section{METODE}

Pengambilan sampel dalam penelitian ini dengan menggunakan metode Purposive Sampling. Jumlah sampel yang diambil dalam penelitian ini adalah sebanyak 100 responden yang merupakan konsumen mataharimall.com di Kota Surakarta. Penelitian ini menggunakan alat analisis berupa uji validitas, uji reliabilitas, uji asumsi klasik, analisa regresi linier berganda, uji t, uji $\mathrm{F}$ dan koefisiendeterminasi.

\section{HASIL UJI}

1. Hasil UjiValiditas

Hasil uji validitas menunjukkan bahwa seluruh item pertanyaan pada kuesioner valid dan reliabel dengan nilai t hitung $>$ ttabel

Tabel 1

Hasil Uji Validitas Variabel Promosi

\begin{tabular}{|c|c|c|c|}
\hline $\begin{array}{c}\text { Pertanya } \\
\text { an Ke }\end{array}$ & r hitung & r tabel & Keputusan \\
\hline 1 & 0,628 & 0,169 & Valid \\
\hline 2 & 0,602 & 0,169 & Valid \\
\hline 3 & 0,601 & 0,169 & Valid \\
\hline 4 & 0,612 & 0,169 & Valid \\
\hline 5 & 0,746 & 0,169 & Valid \\
\hline
\end{tabular}

Sumber : Data Primer yang diolah 
Excellent : Jurnal Manajemen, Bisnis dan Pendidikan

ISSN : 1979-2700

Vol 7, No 1 (2020) ; p.105-114; https://e-journal.stie-aub.ac.id/index.php/excellent

Tabel 2

Hasil Uji Validitas Variabel Kelas Sosial

\begin{tabular}{|c|c|c|c|}
\hline $\begin{array}{c}\text { Pertanya } \\
\text { an ke }\end{array}$ & rHitung & r tabel & Keputusan \\
\hline 1 & 0,536 & 0,169 & Valid \\
\hline 2 & 0,591 & 0,169 & Valid \\
\hline 3 & 0,557 & 0,169 & Valid \\
\hline 4 & 0,568 & 0,169 & Valid \\
\hline 5 & 0,616 & 0,169 & Valid \\
\hline
\end{tabular}

Sumber : Data Primer yang diolah

Tabel 3

Hasil Uji Validitas Citra Merk

\begin{tabular}{|c|c|c|c|}
\hline $\begin{array}{c}\text { Pertanya } \\
\text { an ke }\end{array}$ & rHitung & r tabel & Keputusan \\
\hline 1 & 0,569 & 0,169 & Valid \\
\hline 2 & 0,621 & 0,169 & Valid \\
\hline 3 & 0,593 & 0,169 & Valid \\
\hline 4 & 0,645 & 0,169 & Valid \\
\hline 5 & 0,650 & 0,169 & Valid \\
\hline
\end{tabular}

Sumber : Data Primer yang diolah

Tabel 4

Hasil Uji Validitas Keputusan

\begin{tabular}{|c|c|c|c|}
\hline $\begin{array}{c}\text { Pertan } \\
\text { yaan ke }\end{array}$ & rHitung & r tabel & Keputusan \\
\hline 1 & 0,693 & 0,169 & Valid \\
\hline 2 & 0,613 & 0,169 & Valid \\
\hline 3 & 0,527 & 0,169 & Valid \\
\hline 4 & 0,548 & 0,169 & Valid \\
\hline 5 & 0,615 & 0,169 & Valid \\
\hline
\end{tabular}

Sumber : Data Primer yang diolah

\section{Hasil UjiReliabilitas}

Hasil pengujian dari kelima variabel diatas adalah Reliabel karena semua variabel memiliki koefisien Cronbach's Alpha $>0,60$

Tabel 5

Hasil Uji Reliabilitas

\begin{tabular}{|c|c|c|}
\hline Variabel & $\begin{array}{c}\text { Koefisien } \\
\text { ronbach's Alpha }\end{array}$ & nterpreta si \\
\hline Promosi & 0,693 & Reliabel \\
\hline Kelas Sosial & 0,628 & Reliabel \\
\hline Citra Merk & 0,669 & Reliabel \\
\hline Keputusan & 0,656 & Reliabel \\
\hline
\end{tabular}

Sumber : Data Primer yang diolah 
3. Hasil Uji Asumsi Klasik

a. Uji Normalitas:

Tabel 6

Hasil Uji Normalitas

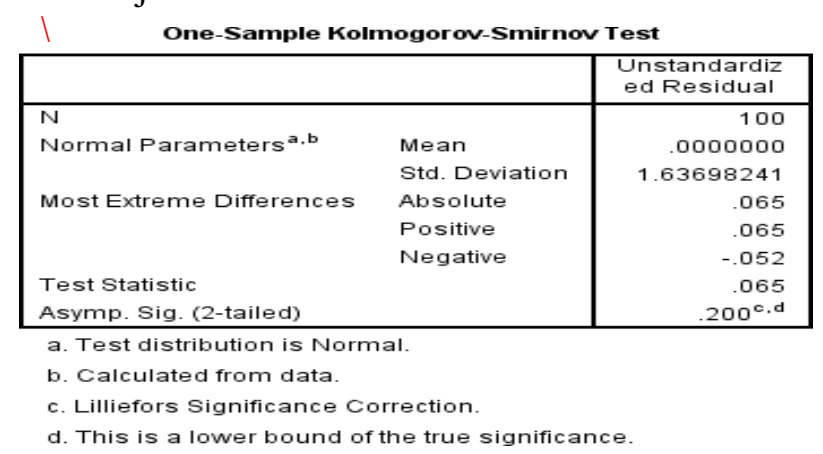

Berdasarkan hasil uji normalitas diatas maka dapat dilihat bahwa data berdistribusi normal karena mempunyai probabilitas $>0.05$

b. Uji Heterokesdastisitas

Gambar 1

Hasil Uji Heterokedastisitas

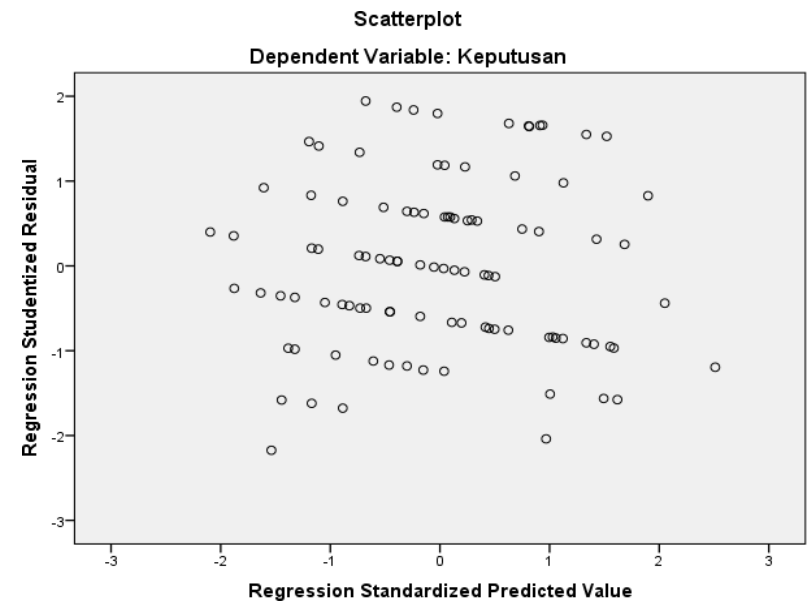

Sumber : Data Primer yang telah diolah

Scatterplot menjelaskan bahwa penyebaran residual adalah tidak teratur, hal tersebut dapat dilihat pada plot yang terpencar dan tidak membentuk pola tertentu sehingga dapat disimpulkan bahwa tidak terjadi Heterokedastisitas pada data yang diteliti.

c. Uji Multikolinearitas

Tabel 7

Hasil Uji Multikolinearitas 
Excellent : Jurnal Manajemen, Bisnis dan Pendidikan

Vol 7, No 1 (2020) ; p.105-114; https://e-journal.stie-aub.ac.id/index.php/excellent

Coefficients $^{\mathrm{a}}$

\begin{tabular}{|c|c|c|c|c|c|c|c|c|}
\hline \multirow[b]{2}{*}{ Model } & & \multicolumn{2}{|c|}{ Unstandardized Coefficients } & \multirow{2}{*}{$\begin{array}{c}\begin{array}{c}\text { Standardized } \\
\text { Coefficients }\end{array} \\
\text { Beta }\end{array}$} & \multirow[b]{2}{*}{$t$} & \multirow[b]{2}{*}{ Sig. } & \multicolumn{2}{|c|}{ Collinearity Statistics } \\
\hline & & $B$ & Std. Error & & & & Tolerance & VIF \\
\hline \multirow[t]{4}{*}{1} & (Constant) & 18,696 & 3,529 & & 5,298 &, 000 & & \\
\hline & Promosi & 141 & .096 & 148 & 1,478 & .143 & 1,000 & 1,000 \\
\hline & Kelas Sosial &,- 071 &, 103 &,- 069 &,- 692 &, 491 & 1,000 & 1,000 \\
\hline & Citra Merk & 091 & 087 & 105 & 1,046 & .298 & 999 & 1,001 \\
\hline
\end{tabular}

a. Dependent Variable: Keputusan

Sumber : Data Primer yang telah diolah

Berdasarkan hasil uji multikolinearitas diatas dapat dilihat bahwa semua variabel independen bebas dari multikolinearitas karena nilai tolerasi $>0,10$ dan $\mathrm{VIF}<10$

d. Uji Autokorelasi

Tabel 8

Hasil Uji Autokorelasi

Model Summary

\begin{tabular}{|l|c|r|r|r|r|}
\hline Model & \multicolumn{1}{|c|}{$\mathrm{R}$} & R Square & $\begin{array}{c}\text { Adjusted R } \\
\text { Square }\end{array}$ & $\begin{array}{l}\text { Std. Error of } \\
\text { the Estimate }\end{array}$ & $\begin{array}{l}\text { Durbin- } \\
\text { Watson }\end{array}$ \\
\hline 1 &, $196^{\mathrm{a}}$ &, 038 &, 008 & 1,662 & 2,439 \\
\hline
\end{tabular}

a. Predictors: (Constant), Citra Merk, Promosi, Kelas Sosial

b. Dependent Variable: Keputusan

Sumber : Data Primer yang telah diolah

Hasil diatas menunjukkan bahwa nilai Durbin - Watson adalah sebesar 1,952 sehingga data yang diteliti bebas dari masalah autokorelasi karena nilai Durbin- Watson berada diantara -2 sampai dengan

$+2,5$.

4. Hasil Uji Regresi LinearBerganda

Tabel 9

Hasil Uji Analisis Regresi Berganda Coefficients $^{\mathrm{g}}$

\begin{tabular}{|c|c|c|c|c|c|c|c|c|}
\hline \multirow[b]{2}{*}{ Model } & & \multicolumn{2}{|c|}{ Unstandardized Coefficients } & \multirow{2}{*}{$\begin{array}{c}\text { Standardized } \\
\text { Coefficients } \\
\text { Beta } \\
\end{array}$} & \multirow[b]{2}{*}{$t$} & \multirow[b]{2}{*}{ Sig. } & \multicolumn{2}{|c|}{ Collinearity Statistics } \\
\hline & & $B$ & Stch Error & & & & Tolerance & VIF \\
\hline 1 & (Constant) & 18,696 & 3,529 & & 5,298 &, 000 & & \\
\hline & Promosi &, 141 &, 096 &, 148 & 1,478 &, 143 & 1,000 & 1,000 \\
\hline & Kelas Sosial & .071 &, 103 & .069 & .692 &., 491 & 1,000 & 1,000 \\
\hline & Citra Merk & 091 & 087 & 105 & 1,046 & 298 & 999 & 1,001 \\
\hline
\end{tabular}

a. DependentVariable: Keputusan

Sumber : Data Primer yang telah diolah

Persamaan bentuk regresi linear berganda sebagai berikut:

$Y=18,696+0,141 X_{1}-0,071 X_{2}+0,091 X_{3}$ 
Hasil penghitungan regresi berganda tersebut dijelaskan sebagai berikut :

a. $(\alpha)=18,696$ menunjukkan bahwa bila variabel Promosi, dan $\mathrm{C}$ itra Merk dianggap konstan, maka Keputusan Konsumen untuk membeli produk di mataharimall.com meningkat dengan asumsi variabel laintetap.

b. $\beta_{1}=0,141$ menunjukkan bahwa variabel Promosi berpengaruh positif terhadap Keputusan pembelian, artinya apabila Promosi meningkat maka Keputusan Pembelian juga meningkat dengan asumsi variabel laintetap.

c. $\beta_{2}=-0,071$ menunjukkan bahwa variabel Kelas Sosial berpengaruh negatif terhadap Keputusan pembelian, artinya apabila Kelas Sosial meningkat maka Keputusan Pembelian menurun dengan asumsi variabel laintetap

d. $\beta_{3}=0,091$ menunjukkan bahwa variabel Citra Merk berpengaruh positif terhadap Keputusan pembelian, artinya apabila Citra Merk meningkat maka Keputusan Pembelian juga meningkat dengan asumsi variabel laintetap.

5. Hasil Ujit

Tabel 10 Hasil Uji t

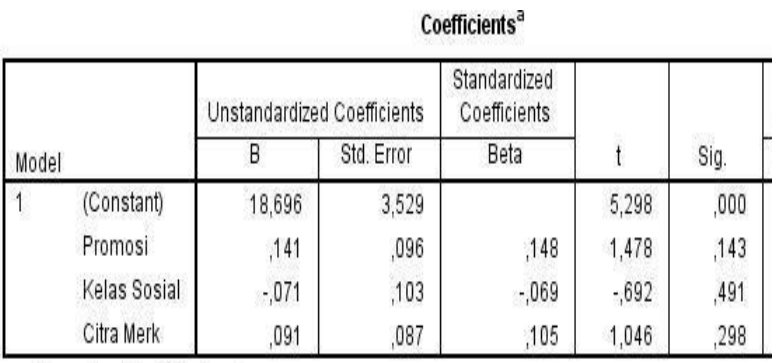

a. DependentVariable: Keputusan

Hasil penghitungan untuk variabel citra merk adalah sebesar 1046 dengan $\mathrm{P}_{\text {value }}$ sebesar 0,298>0,05. Hal ini berarti variabel citra merk berpengaruh tidak signifikan terhadap Keputusan pembelian di mataharimall.com

6. Hasil Uji Koefisien Determinasi $\left(\mathrm{R}^{2}\right)$

Tabel 11 hasil Uji $\mathrm{R}^{2}$

Model Summary

\begin{tabular}{|l|c|r|r|r|r|}
\hline Model & $R$ & R Square & $\begin{array}{c}\text { Adjusted R } \\
\text { Square }\end{array}$ & $\begin{array}{l}\text { Std. Error of } \\
\text { the Estimate }\end{array}$ & $\begin{array}{l}\text { Durbin- } \\
\text { Watson }\end{array}$ \\
\hline 1 &, $196^{\mathrm{a}}$ &, 038 &, 008 & 1,662 & 2,439 \\
\hline
\end{tabular}

a. Predictors: (Constant), Citra Merk, Promosi, Kelas Sosial

b. Dependent Variable: Keputusan

Berdasarkan Uji $\mathrm{R}^{2}$ yang dilakukan diperoleh hasil bahwa nilai $\mathrm{R}^{2}$ adalah sebesar 0,008 yang berarti nilai $\mathrm{R}^{2}$ jauh dari angka 1 . Artinya variabel independen yang dipilih dalam penelitian ini kurang dapat menerangkan dengan baik variabel dependen. Selain itu, hasil uji $\mathrm{R}^{2}$ juga memiliki arti bahwa variabel - variabel independen mempengaruhi keputusan pembelian di mataharimall.com sebesar $8 \%$, sedangkan sisanya sebesar $92,20 \%$ dipengaruhi oleh faktorlain.

Dari pengujian yang dilakukan diperoleh hasil sebagai berikut :

a. Hasil penghitungan untuk variabel promosi adalah sebesar 1,478 dengan $\mathrm{P}_{\text {value }}$ sebesar 0,143 $>0,05$. Hal ini berarti variabel promosi berpengaruh tidak signifikan terhadap Keputusan pembelian di mataharimall.com

b. Hasil penghitungan untuk variabel kelas sosial adalah sebesar -0,692 dengan $\mathrm{P}_{\text {valuesebesar }}$ $0,491>0,05$. Hal ini berarti variabel kelas sosial berpengaruh tidak signifikan terhadap Keputusan pembelian di mataharimall.com 


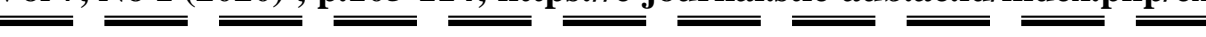

\section{PEMBAHASAN}

1. Promosi berpengaruh positif tidak signifikan terhadap Keputusan Pembelian di mataharimall.com

Promosi berpengaruh positif pada keputusan pembelian di mataharimall tetapi tidak signifikan, hal ini berarti promosi yang dilakukan oleh mataharimall.com telah mampu menargetkan konsumen untuk membeli secara online tetapi tidak nyata atau tidak signifikan berpengaruh. Hal ini mungkin disebabkan karena konsumen mataharimall.com masih membandingkan antara mataharimall.com dengan website jual beli online sejenis dan belum teguh memilih mataharimall.com. selain itu, Promosi yang dilakukan mataharimall.com perlu ditingkatkan karena walaupun konsumen telah mengetahui dan melakukan transaksi pada website mataharimall.com, namun konsumen belum terlalu menyukai jenis promosi yang diberikan, dilihat dari hasil diatas.

2. Kelas sosial berpengaruh negatif tidak signifikan terhadap Keputusan Pembelian di mataharimall.com

Kelas sosial berpengaruh negatif dan tidak signifikan artinya terjadi anomali dari penelitian terdahulu. Bila kelas sosial meningkat keputusan pembelian di mataharimall.com menurun, hal ini berarti semakin tinggi kelas sosial konsumen, semakin mereka tidak melakukan keputusan pembelian di mataharimall.com. Hal ini artinya mataharimall.com memiliki kelas sosial yang cukup luas terutama kalangan menengah.

3. Citra merk berpengaruh positif tidak signifikan terhadap Keputusan Pembelian di mataharimall.com

Citra merk berpengaruh positif tetapi tidak signifikan terhadap Keputusan pembelian di mataharimall.com, hal ini berarti konsumen perduli pada citra merk matahari,maupun citra merk produk yang dijual di mataharimall.com, tetapi tidak nyata atau tidak signifikan pengaruhnya. Hal ini harus diperbaiki oleh mataharimall.com agar konsumen bangga dan dapat menyatakan bahwa berbelanja di mataharimall.com adalah sesuatu yang terjamin dari segi apapun.

\section{KESIMPULAN}

1. Promosi berpengaruh positif tidak signifikan terhadap keputusan pembelian di mataharimall.com

2. Kelas sosial berpengaruh negatif tidak signifikan terhadap keputusan pembelian di mataharimall.com

3. Citra merk berpengaruh positif tidak signifikan terhadap keputusan pembelian di mataharimall.coml

4. Promosi, Kelas sosial dan Citra merk hanya mampu menjelaskan Keputusan pembelian di Mataharimall.com sebesar 8\%, sisanya 92\% dipengaruhi oleh hal - hal lain misalnya, Harga dan Kualitas Pelayanan

\section{SARAN}

Dari hasil diatas, dapat dilihat bahwa seluruh variabel berpengaruh tidak signifikan, maka perlu diupayakan berbagai hal oleh manajemen mataharimall.com agar konsumen dapat menyatakan bahwa mereka bangga dan yakin berbelanja di mataharimall.com. Hal yang dapat dilakukan diataranya :

1. Melakukan survey pasar untuk melihat minat konsumen khususnya konsumen matahari untuk berbelanja melalui website online dan mempelajari website online sejenis untuk dapat melakukan strategi pemasaran yang baik

2. Menentukan pangsa pasar yang akan ditarget, apakah dari kalangan menengah atau kalanganatas

3. Membuat strategi pemasaran yang lebih baik dan menarik hati konsumen sehingga yakin berbelanja dimataharimall.com 


\section{KETERBATASAN}

Penelitian ini memiliki berbagai keterbatasan yang dapat diperbaiki di penelitian selanjutnya diantaranya :

1. Penelitian ini terbatas pada konsumen mataharimall.com yang ditemui dan diberikan kuesioner secara langsung, dan belum menyasar pada konsumen online yang dapat diberikan kuesioner secaraonline

2. Penelitian ini terbatas pada konsumen mataharimall.com di kota Surakarta yang belum dapat mewakili seluruh populasi dari konsumenmataharimall.com

3. Promosi, Kelas sosial dan Citra merk hanya mampu menjelaskan Keputusan pembelian di Mataharimall.com sebesar $8 \%$, sisanya $92 \%$ dipengaruhi oleh hal - hal lain yang tidak dijelaskan dalam penelitian ini misalnya, Harga, kualitas produk dan Kualitas Pelayanan. Hal ini mungkin disebabkan karena pengambilan sampel yang belum mampu mewakili Populasi konsumen secara keseluruhan diIndonesia.

\section{DAFTAR PUSTAKA}

Aaker, David A. Dan Alexander L. Biel. 2009. Brand Equity And Advertising: Advertising Role In Building Strong Brand. Lawrence Erlbaum Associates. Inc., Hillsdale

Ajeng Peni Hapsari (2008) “Analisis Perbandingan Penggunaan Celebrity Endorser Dan Tipical Person Endorser Iklan Televisi Dan Hubungannya Dengan Keputusan Pembelian produk". Jurnalfakultas Ekonomi Universitas PadjadjaranBandung.

Ardyanto Denni Dan Heru Susilo. 2015. PENGARUH KEMUDAHAN DAN KEPERCAYAAN MENGGUNAKAN E- COMMERCE TERHADAP KEPUTUSAN

ONLINE (Survei Pada Konsumen Www.Petersaysdenim.Com). PEMBELIAN Administrasi Bisnis (JAB)|Vol. 22 No.1. Mei2015

Augusty, Ferdinand. 2006. Metode Penelitian Manajemen. Semarang: Badan. Penerbit Universitas Diponegoro.

Buchari Alma. 2007, Manajemen Pemasaran \& Pemasaran Jasa. Bandung: CV. Alfabeta

Cannon, Perreault Dan Mccarthy (2008). Manajemen Pemasaran, Jakarta: Salemba Empat

Eddy Soeryanto Soegoto, 2009, Enterpreneurship, Edisi Pertama, Jakarta : PT. Elek MediaKomputindo

Ghozali, Imam. 2009. “Aplikasi Analisis Multivariate Dengan Program SPSS “. Semarang : UNDIP.

Giantara Mariani Shoshana Dan Jesslyn Santoso PENGARUH BUDAYA, SUB BUDAYA, KELAS SOSIAL, DAN PERSEPSI KUALITAS TERHADAP PERILAKU KEPUTUSAN PEMBELIAN KUE TRADISIONAL OLEH MAHASISWA DI SURABAYA. Jurnal Hospitality Dan Manajemen Jasa Vol. 2 No. 1

Hermawan Kartajaya.2010.Brand Operation The Official MIM Academy Course Book. Jakarta : Esensi Erlangga Group

Husein, Umar. (2000). Riset Pemasaran Dan Penilaian Konsumen. Jakarta: PT Gramedia.

Jamaludin Achmad, Zainul Arifin Dan Kadarisman Hidayat. 2015. PENGARUH PROMOSI ONLINE DAN PERSEPSI HARGA TERHADAP KEPUTUSAN PEMBELIAN (Survei 
Pada Pelanggan Aryka Shop Di Kota Malang). Jurnal Administrasi Bisnis (JAB)|Vol. 21 No.1 April 2015

Kasimin, Patricia Dhiana Dan Muh Mukery Warso. 2015. EFFECT OF DISCOUNTS, SALES PROMOTION AND MERCHANDISING ON IMPULSE BUYING AT TOKOINTAN PURWOKERTO. Journal Of Management Vol.1 No. 1. ISSN : 2502-7689

Kotler, Philip Dan Kevin Lane Keller, 2008. Manajemen Pemasaran, Jilid 1,. Penerbit Erlangga. Jakarta

Kuntjojo. 2009. Metode Penelitian. Kediri: Universitas Nusantara PGRI

Moly, Vivi alvionita. 2014. PENGARUH CITRA MEREK DAN KUALITAS PRODUK TERHADAP KEPUTUSAN PEMBELIAN HANDPHONE NOKIA (Studi Kasus Toko Mars Cell Klandasan, Balikpapan). Ejournal Psikologi, 2, (2) 2014 : 258 - 268.

Muhammad Saikoo, Hari, Dan Bulan. 2016. Pengaruh Promosi, Harga Dan Kualitas Produk Terhadap Minat Beli Konsumen Kerudung Rabbani . Jurnal Ilmu Administrasi Bisnis Vol. 5 No. 1

Nurhayati, Siti MS. (2012). Metodologi Penelitian Praktis.Pekalongan

Oktavianingrum, Maria M Minarsih Dan Moch. Mukeri Warso. 2015. EFFECT OF RISK PERCEPTION, TRUST,AND PSYCHOLOGY OF YOUTH CLOTHING ONLINE PURCHASE DECISION AMONG UNIVERSITY STUDENTS PANDANARAN SEMARANG. Journal Of Management Vol.1 No. 1. ISSN : 2502- 7689

Santosa Budi Purbayu Dan Ashari.2005.Analisis Statistik Dengan Microsoft. Axcel\& SPSS. Andi Offset. Yogyakarta

Setiawan Ujang Setiawan, Patricia Dhiana Dan Andi Tri Haryono. 2015. PENGARUH CITRA MEREK, HARGA, KUALITAS PRODUK DAN GAYA HIDUP TERHADAP KEPUTUSAN PEMBELIAN HANDPHONE BLACKBERRY GEMINI (Studi Pada Mahasiswa Mahasiswi Fakultas Ekonomi Universitas Pandanaran Semarang), Jurnal Manajemen Pemasaran 2015|4

Schiffman Dan Kanuk. 2008. Perilaku Konsumen. Edisi 7. Jakarta :Indeks.

Surachman. 2008. Dasar-Dasar Manajemen Merek (Alat Pemasaran Untuk Memenangkan Persaingan). Malang: Bayumedia Publishing

Rangkuti, Fredy, “Strategi Promosi Yang Kreatif”, PT. Gramedia Pustaka Utama, Jakarta, 2009

Talcott Persons, 2010. Dismissal Of Parsons In The New Economic Sociology.” American Journal Of Economics And Sociology. Volume 65.

Tjiptono, Fandy, 2008, Strategi Pemasaran, Edisi 3, ANDI: Yogyakarta Http://BlogDefinisi.Blogspot.Co.Id/2016/04/Pengertia $n$ definisi-Dan-Jenis-Jenis.Html). 